\title{
Proses Awal dalam Penghasilan Komposisi “Kelampan Bajang” dengan Mengadaptasi Struktur Musik Pop Suku Sasak Lombok
}

\author{
Sapriadi $^{1}$; Chamil Arkhasa Nikko Mazlan ${ }^{2}$; Affendi Ramli ${ }^{3}$ \\ 1,2,3 Fakulti Muzik dan Seni Persembahan, Universiti Pendidikan Sultan Idris, Perak, Malaysia. \\ ${ }^{(*)} \bowtie$ (e-mail) oyoksapriadi17@gmail.com¹; jazzerlogy@gmail.com²; affendi@fmsp.upsi.edu.my ${ }^{3}$
}

\begin{abstract}
Abstrak
Komposisi musik berjudul Kelampan Bajang, merupakan narasi utama tema komposisi tentang kisah perjalanan pemuda suku sasak yang secara semiotik tergambar dalam tiga waktu berbeda yaitu pagi, siang, dan malam. Komposisi tersebut muncul oleh karena beberapa fenomena yang ditemukan antara lain 1) tidak ada lagu berbahasa Sasak yang lengkap dalam transkrip dan aransemen, 2) banyak musisi mengaransemen lagu dalam bahasa Sasak tetapi sering menimbulkan kontroversi pada lirik dan musik, 3) banyak musisi muda berbakat mengcover ulang lagu-lagu noname pada beberapa lagu yang dibawakan oleh banyak penyanyi pop di Lombok, 4) banyak lagu pop sasak tetapi sebagian besar tidak merepresentasikan budaya daerah dari sisi lirik dan musik. Tulisan ini bertujuan untuk menjelaskan proses awal komposisi musik dengan tema Kelampan Bajang meliputi 1) Bekuliq, 2) Bekayaq, 3) Matur Tampiasih, 4) Sepi Alam Dese, 5) Lalo Midang, dan 6) Merariq. Semua llirik lagu ditulis menggunakan bahasa sasak. Penelitian menggunakan metode autoetnografi untuk membahas permasalahan, bagaimana ide penciptaan komposisi musik dapat disejajarkan sebagai keragaman budaya musik di Lombok. Setelah melakukan kajian yang mendalam, penulis menemukan kesimpulan bahwa untuk mewujudkan suatu karya komposisi yang bisa merefresentasikan budaya daerah dan tidak menimbulkan kontroversi dikalangan masyarakat yaitu 1) penulis menyelipkan eksplorasi motif melodi pelog dan slendro pada bagian melodi vokal sebagai identitas kedaerahan, 2) penulis menyelipkan motif melodi pelog dan slendro pada bagian aransemen musik, dan yang ke 3) penulis menggunakan lirik berbahasa daerah yang baik dan benar yang sesuai dengan budaya daerah di Lombok.
\end{abstract}

Kata kunci: Komposisi musik; kajian seni kreatif; musik pop sasak; lombok; autoetnografi.

\section{(c) (i) (2)}

This work is licensed under a Creative Commons Attribution-ShareAlike 4.0 International License. Copyright (C 2021 Sapriadi; Chamil Arkhasa Nikko Mazlan; Affendi Ramli

\section{Proses Artikel}

Diterima 14-08-2021; Revisi 09-09-2021; Terbit Online 17-12-2021 


\begin{abstract}
The musical composition, entitled Kelampan Bajang, is the main narrative of the composition theme about the story of the journey of the young Sasak tribe which is semiotically depicted in three different times, namely morning, afternoon, and night. This composition emerged due to several phenomena found, including 1) there are no complete Sasak songs in transcripts and arrangements, 2) many musicians arrange songs in Sasak but often cause controversy in lyrics and music, 3) many talented young musicians cover repeating noname songs on several songs performed by many pop singers in Lombok, 4) many sasak pop songs but most of them do not represent local culture in terms of lyrics and music. This paper aims to explain the initial process of musical composition with the theme Kelampan Bajang including 1) Bekuliq, 2) Bekayaq, 3) Matur Tampiasih, 4) Sepi Alam Dese, 5) Lalo Midang, and 6) Merariq. All song lyrics are written in the Sasak language. The research uses the autoethnographic method to discuss the problem, how the idea of creating musical compositions can be aligned with the diversity of musical culture in Lombok. After conducting an in-depth study, the author concluded that in order to create a compositional work that could represent regional culture and not cause controversy among the public, namely 1) the author inserted an exploration of the pelog and slendro melodic motifs in the vocal melody section as regional identity, 2) the author inserted the motif the melodies of pelog and slendro in the musical arrangement section, and 3) the author uses good and correct local language lyrics that are in accordance with the regional culture in Lombok.
\end{abstract}

Keywords: Music composition; creative arts research; sasak pop music; lombok; autoethnography. 


\section{Pendahuluan}

Perkembangan musik semakin mudah diakses melalui berbagai platform secara online seperti spotify, youtube dan website lainnya. Dengan demikian, situasi ini memberikan ruang dan kesempatan untuk menikmati musik dari berbagai genre, dari genre modern hingga tradisional. Secara tidak langsung, kehadiran teknologi ini membantu mewujudkan budaya baru dalam aktivitas bermusik (Abimanyu \& Harwanto, 2019). Dari sudut yang berbeda, ruang keragaman musik ini membuka dimensi yang tidak hanya melihat musik sebagai hiburan tetapi juga sebagai proses pembelajaran.

Hidayatulah memberikan pandangannya bahwa cara berpikir dalam pendidikan musik terbagi menjadi dua pemikiran, yaitu 1) pendidikan dalam musik, dan 2) pendidikan melalui musik. Merujuk pada gagasan pendidikan musik, salah satu cara pendidikan musik melalui penelitian dan pemasukan karya musik. Beberapa contoh pendidikan musik adalah dengan produksi musik kontemporer, seperti komposisi musik musik gamelan Jawa tradisional dan permainan lagu dengan alat musik modern (Abimanyu \& Harwanto, 2019), Lagu Melayu Asli dan harmonisasi gitar jazz (Mazlan \& Abdullah, 2020; Mazlan, 2021) dan masih banyak lagi hasil penelitian yang mengarah pada hibriditas dua budaya musik yang berbeda. Evolusi musik dan konsep hibriditas sudah ada sejak lama, misalnya gamelan dan musik Eropa (Sasongko \& Supriyadi, 2021).

Dari hasil kajian literatur juga menunjukkan banyak kajian yang membahas tentang evolusi dan hibriditas musik tradisional, tentang bagaimana kekayaan harmoni improvisasi pada musik tradisional dengan musik jazz dan musik modern lainnya (Sasongko \& Supriyadi, 2021), (Mazlan, C. A. N, 2021). Pada sisi yang lain berkaitan dengan sistem pembelajaran pada situasi pendidikan dengan situasi pandemi saat ini, beberapa penelitian juga menghasilkan konsep pembelajaran teknik dasar seni musik tradisional dengan menggunakan metode aplikasi google clas sebagai cara yang praktis dalam memanfaatkan teknologi revolusi industry 4.0, demikian juga dengan penelitian ilmu pengetahuan musik dengan reharmonisasi musik tradisi dalam reportoar modern (Mazlan C. A. N., Abdullah, \& Uyub, 2021), (Kristanto, 2020), (Mazlan C. A. N, Abdullah, \& Uyub, 2021), (Mazlan C. A. N, \& Abdullah, 2020). Beberapa penelitian juga bisa di gunakan sebagai acuan bahwa dengan pertunjukan konser musik bisa memberikan satu edukasi dalam mengapresiasi masyarakat dengan musik tradisi, terutama pada jenis musik baru yang menggabungkan idiom-idiom musik tradisi dan modern sebagai bentuk kreatifitas seniman dalam berkarya menemukan musik bentuk baru yang dapat di banggakan oleh masyarakat, khususnya pendukung kesenian itu sendiri dan secara tidak langsung untuk melestarikan budaya musik nusantara secara turun temurun (Asriyani \& Rachman, 2019), (Wimbrayardi, 2019).

Di ndonesia terdapat beraneka ragam kekayaan seni dan budaya, sehingga dengan kepekaan seni menjadikan manusia yang memiliki sensitifitas perasaan untuk sesamanya dan lingkungannya. Menjadi manusia yang mampu beradaptasi dan menjaga nilai-nilai kearifan lokal ditengah perubahan-perubahan yang terbentuk dari dinamika perkembangan zaman (Kristanto, 2020). dan masyarakat harus memiliki keinginan untuk mempertahankan seni itu, baik seni musik maupun seni lainnya. Namun, tidak semua genre musik bernasib sama. Dalam konteks ini, fokus pada musik yang menggunakan bahasa penghubung. Bahkan, lirik dan gubahan musik yang dihasilkan, sering dipandang tidak sejalan dengan budaya dan tradisi 
masyarakat Sasak di Lombok. Parahnya lagi, 40 video klip lagu Sasak dilarang disiarkan di radio dan televisi, KPID NTB Blokir 40 Lagu Sasak, 2017, (Suarantb.com, 2017)

Kontroversi yang berujung pemblokiran lagu-lagu Sasak sebenarnya sudah dilakukan sejak awal, karena ada masalah konten yang digunakan dengan isu pembodohan dan pornografi, seperti diungkapkan oleh sekretaris Forum Peduli Nilai Seni dan Budaya Lombok (FPNSBL), Yudi Yogaswara dalam (Kompas.com, 2009) dan Badrun Am, Ketua Komisi Penyiaran Indonesia Daerah (KPID) oleh (Kompas.com, 2009). Yang mempengaruhi anak kecil yang beranjak dewasa bisa terpengaruh dengan lirik-lirik yang kurang sopan tersebut. Jika tidak diatasi, masalah sosial yang lebih besar akan terjadi di masa yang akan datang (Kompas.com, 2009).

Di sisi lain, ada pihak yang sangat apresiatif sekali terhadap berkembangnya lagu-lagu daerah sasak karya seniman daerah ini, tetapi proses kreatif itu tidak harus melanggar tata nilai yang berlaku di tengah masyarakat, tambah Badrun Am dalam (Anton, 2009). Tidak hanya mengandung lirik yang kurang pantas, musik dan lirik berbahasa daerah sasak ini juga banyak menggunakan konotasi negatif, seperti lagu yang berjudul "Jual Cobek" yang dinyanyikan oleh vokalis Jumpring, Jhon Kursi Roda (Awaludin, 2014). Hal ini pula yang menjadi ketertarikan peneliti untuk menuangkan ide dan gagasan kedalam sebuah karya yang berjudul "Kelampan Bajang".

Gagasan penciptaan seni ini melalui pengamatan penulis sendiri, sebagai musisi dan guru musik di Lombok, ditemukan bahwa kurangnya minat generasi muda untuk menggali dan menciptakan karya musik menggunakan bahasa Sasak, permasalahan ini disebabkan karena kurangnya pemahaman pendidikan musik. Argumentasi ini juga didukung oleh Ahmad Bages, pencipta musik dangdut sasak yang menyatakan bahwa 99 persen pencipta musik sasak di Lombok tidak memiliki pengetahuan dan literasi musik, seperti notasi dan sebagainya (Suryanto, 2006). Jika kita tidak mengerti apa yang sedang dimainkan, bagaimana kita memastikan bahwa informasi yang disampaikan dipahami? Jika Anda tidak mengerti, sedikit situasi ini membuat minat untuk mendalami musik berkurang. Ini juga karena sebagian besar musik tradisional sasak tidak didokumentasikan. Keadaan ini juga berlaku untuk semua jenis musik tradisional, karena pada dasarnya pembelajaran musik dilakukan dengan tradisi lisan, yaitu meniru apa yang dipelajari dari demonstrasi (Shah \& Masumi, 2016); (Abu Bakar N. A, 2014); (Shah \& Adam Masumi, 2016); (Isyak, 2018); (Rosly, 2018); (Ayderova, Wong, Augustine, \& Arshad, 2020); (Chamil Arkhasa Nikko Mazlan et al., 2020)

Berkaitan dengan itu ada beberapa permasalahan yang peniliti temukan dilapangan yaitu 1) Tidak ada lagu berbahasa Sasak yang lengkap dalam transkrip atau aransemennya, 2) banyak seniman yang menghasilkan komposisi lagu dalam bahasa Sasak namun sering menimbulkan kontroversi dalam lirik dan musik, 3) musisi muda berbakat adalah lebih cenderung memainkan lagu yang sudah ada daripada menciptakan karya lagu mereka sendiri, 4) banyak lagu pop daerah yang sudah ada, tetapi sebagian besar dalam beberapa lagu tidak merefresentasikan budaya lokal secara lirik dan musik. Untuk itu peneliti ingin membuat komposisi baru yang berjudul Kelampan Bajang untuk memberikan edukasi kepada masyarakat luas dan Lombok pada khususnya tentang bagaimana teknik membuat lagu daerah dengan memasukkan unsur-unsur yang menjadi identitas suatu daerah dengan membuat motif melodi pada melodi utama/vocal, pada musik dan aransemenya, serta menempatkan frase dalam lirik berbahasa daerah dengan baik dan benar sesuai dengan 
budaya daerah setempat. Kelampan yang berarti perjalanan dan bajang berarti anak muda, sehingga Kelampan Bajang dapat diartikan sebagai kisah perjalanan anak muda suku sasak. Narasi kisah pemuda tersebut kemudian diceritakan dengan tiga suasana atau dengan waktu yang berbeda-beda, dengan menggunakan instrumen pendukung sehingga bisa mewakili suasana dan perasaan dalam setiap komposisi lagu ini.

Karya musik sasak, baik tradisional, kontemporer maupun modern harus dipelihara dan diproduksi sesuai dengan nilai budaya yang ada. Hal ini dikarenakan, karya musik tradisional dapat dijadikan sebagai produk yang dapat dimaknai dalam mengasah kreativitas, inovatif dan produktif dalam menghasilkan karya-karya baru (Wimbrayardi, 2019), serta mengajak generasi muda dan menghasilkan generasi yang terampil dalam sosial budaya.

Dari permasalahan yang diangkat, peneliti berharap penelitian ini bertujuan untuk menambah khazanah musik di Lombok dengan menciptakan sebuah komposisi berjudul Kelampan Bajang sebagai sebuah genre musik pop sasak. Artikel ini juga membahas proses awal dalam merancang pembuatan komposisi, yaitu ide-ide yang bersifat konseptual. Hal ini karena penelitian, khususnya dalam karya seni kreatif adalah studi yang berkelanjutan. Bagian selanjutnya memaparkan metode yang digunakan, dilanjutkan dengan ide awal komposisi yang akan dihasilkan dan pembahasan mengenai pengalaman awal penulis dalam merancang penelitian yang dilakukan.

\section{Metode}

Penelitian ini menggunakan metode autoetnografi. Untuk memudahkan dalam bekerja, peneliti juga menggunakan desain studi seni kreatif (creative art research), meliputi dua bagian, yaitu produk yang mengacu pada komposisi Kelampan Bajang dan deskripsi karya kreatif, yaitu dokumen yang menggambarkan kembali proses produksi komposisi dalam bentuk karya tulis ilmiah. Penelitian ini menggunakan metode analisis musikologi dan analisis secara kualitatif.

Setelah menemukan ciri-ciri penting yang sesuai dengan musik sasak, penulis menggarap ide-ide musik dalam menghasilkan komposisi yang berjudul Kelampan Bajang. Selain karya komposisi, penulis juga akan mencatat proses produksi dalam sebuah buku yang berbentuk catatan harian. Catatan ini penting untuk penulis lampirkan dalam karya tulis ilmiah yang akan dihasilkan. Selain penulisan ilmiah ini, setiap penelitian dalam karya kreatif disertai dengan produk, yaitu dalam penelitian ini mengacu pada komposisi Kelampan Bajang. Data yang ada dalam penelitian ini diperoleh dari berbagai sumber, terdiri dari sumber dokumen seperti audio dan videografi, artikel jurnal yang berkaitan dengan musik sasak dan musik pop yang menggunakan bahasa sasak.

Selain penelitian seni kreatif seperti practice-led maupun practice-based lebih banyak menggunakan metode yang dikenal sebagai autoetnografi (Gauntlett, 2021; Haynes, 2018). Autoetnografi ini juga merupakan pendekatan yang digunakan untuk memahami suatu budaya melalui pengalaman pribadi (Zitierung, Ellis, Adams, \& Bochner, 2011). Penelitian yang dilakukan oleh penulis yaitu melalui proses menghasilkan komposisi dan menggali ideide yang dapat membantu dalam menghasilkan karya. Oleh karena itu, dalam penelitian ini. Ide ini juga sejalan dengan konsep dalam pendekatan kualitatif, yaitu merefleksikan diri dan 
pengalaman pribadi, menjadikan seorang peneliti bukan hanya sekedar pengamat pasif dalam penelitian yang dilakukan (Creswell, 2016).

Hasil

Deskripsi Karya Komposisi Kelampan Bajang

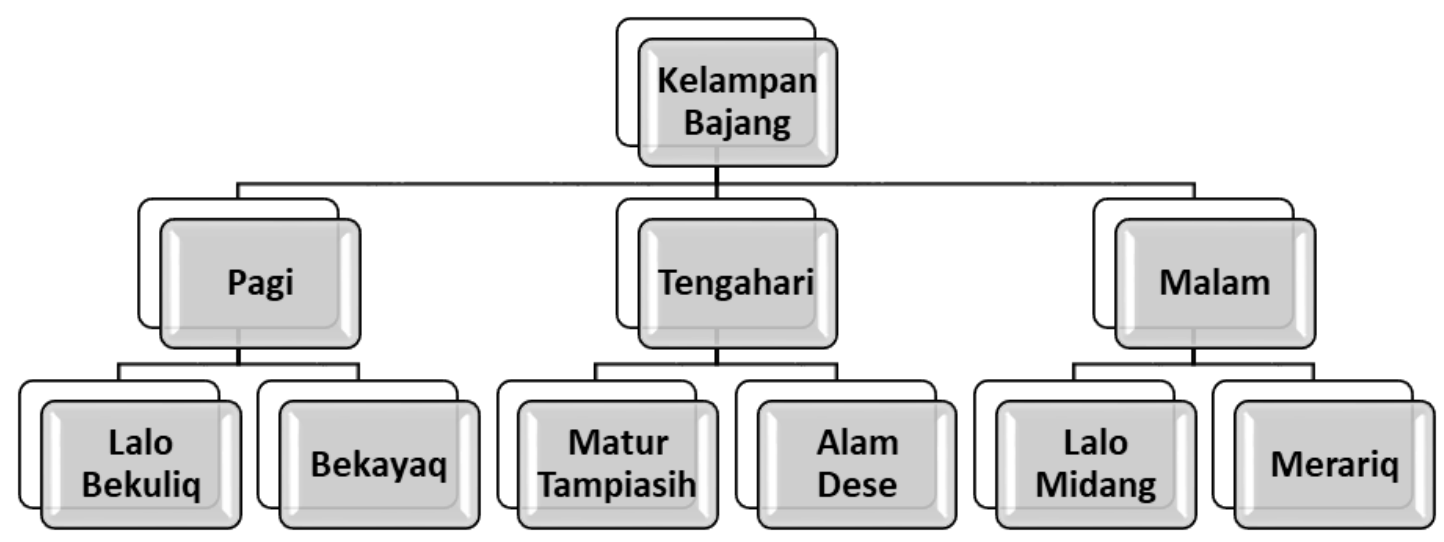

Gambar 1. Pembahagian Komposisi Dalam Kelampan Bajang

Gambar 1 di atas menunjukkan rincian pembagian dalam tema utama komposisi yang berjudul Kelampan Bajang. Kelampan berarti perjalanan dan Bajang berarti anak muda. Gabungan dari kedua kata tersebut menjadi Kelampan Bajang, yang secara semiotika merupakan sebuah kisah tentang perjalanan tentang pemuda suku sasak di Lombok. Kisah pemuda tersebut kemudian diceritakan dari tiga suasana dan waktu yang berbeda-beda, yaitu pada waktu pagi, siang dan malam. Dalam tiga waktu yang berbeda, ia memiliki masingmasing dua komposisi yang berbeda. Berikut adalah deskripsi gambaran awal sub topik komposisi dari tema lagu kelampan bajang:

\section{Komposisi 1: Lalo Bekuliq}

Lalo Bekuliq merupakan tema yang menceritakan kehidupan anak muda sasak yang antusias menyambut pagi hari. Desain awal komposisi musik ini akan mencerminkan suasana pagi, dan diwujudkan dengan motif melodi pada intro menggunakan not 1/16 dalam tangga nada pelog. Lagu ini menggunaan beberapa alat musik seperti drum, gitar, keyboard, bass gitar dan kuartet gesek (string quartet).

komposisi bekuliq berdurasi 5 menit menggunakan tempo moderato dengan motif ritme pada instrumen drum yang lebih padat. Nuansa musik pada bagian lagu ini terasa bersemangat dengan perpaduan unsur motif ritme pada instrument drum dengan kombinasi string dan motif melodi slendro (DO-RE-MI-SOL-LA) minimalis dengan instrumen keyboard menjadikan lagu ini terasa bersemangat. Bentuk lagu ini terdiri dari bentuk $A$ yang memiliki frase anteseden dan frase konsekuen dan bentuk B yang memiliki frase anteseden dan konsekuen, dengan menempatkan eksplorasi melodi slendro pada bagian interlude. Komposisi ini menggunakan akor 1 kres (\#) Mayor. Pola ritme musik pada lagu ini terasa agak enerjik dan bergairah dengan petern drum pada intro dengan sukat 4/4. Perpaduan ritme, 
melodi bernuansa sasak pada awal lagu dengan pola frase anteseden dan konsekuen dengan motif melodi yang sederhana menjadikan lagu ini terdengar bersemangat dengan lirik kedaerahan yang merakyat.
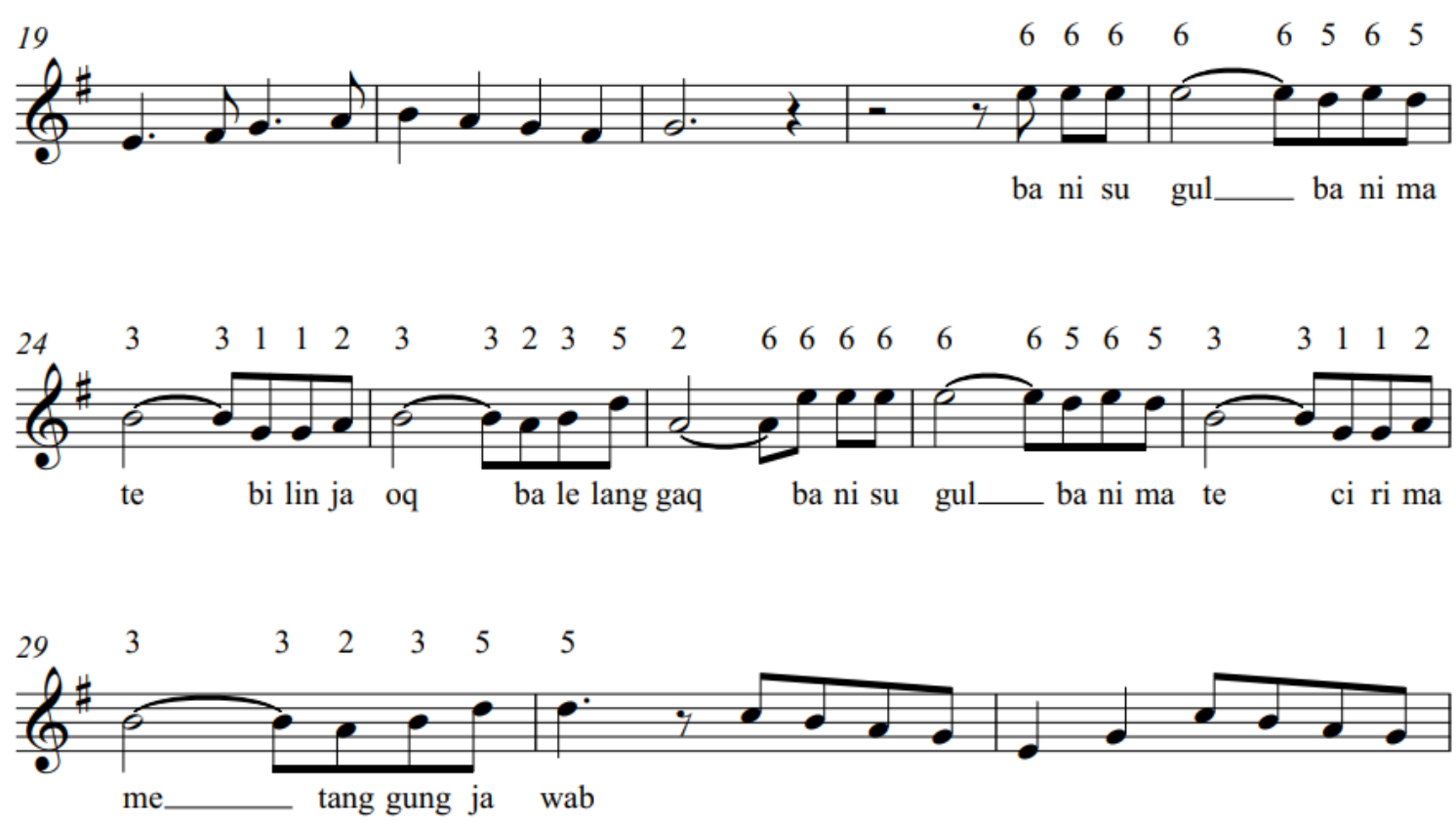

\section{Gambar 2: Potongan Melodi Vocal Bekuliq Pada Bagian Reff Dengan Menggunakan Tangga Nada Slendro (1-2-3-5-6).}

\section{Komposisi 2: Bekayaq}

Beralih ke komposisi kedua, bertema kehidupan anak muda di pagi hari. Suasana ini diilustrasikan dengan penggunaan melodi bernuansa tradisional sasak. Instrumen yang digunakan adalah gitar, gitar bass, keyboard, vokal dan saron. Istilah bekayaq yang memiliki arti menyanyikan lagu dalam bahasa daerah sasak dengan makna unsur tradisional yang ada di dalamnya.

Komposisi lagu saat ini berdurasi 4 menit 17 detik dengan 92 birama dalam tempo Andante menggunakan tangga nada 3 kres (\#) Mayor. Bentuk komposisi ini terdiri dari 2 bagian yaitu bentuk $A$ dan $B$. pada bagian intro terdiri dari 16 birama, bentuk $A$ terdiri dari 16 birama, bentuk $A^{\prime} 16$ birama, dan pada bentuk $B$ terdiri dari 16 birama.

Pada bagian interlude terdapat 16 birama melodi dalam instrumen khas sasak yang berjalan berbarengan secara paralel dengan melodi vocal, proses ini disebut bekayaq atau melantunkan lirih dan harapan pada lagu. Bagian A bersifat repetitif, dalam satu kalimat melodi lagu terdapat 3 motif ( $m 1, m 2$ dan $m 3$ ) melodi yaitu 2 birama $m 1,2$ birama $m 2$ sebagai frase anteseden kemudian $\mathrm{m} 3$ menjadi frase konsekuen. kemudian ke bagian $\mathrm{B}$ dua kali pengulangan saja sebanyak 14 birama diakhiri dengan pengulangan motif melodi/sekuen 4 birama dan lagu berakhir. Pada bagian B terdapat 4 birama anteseden dan 4 birama 
konsekuen, dan di mainkan 2 kali, sehingga di bagian B terdapat 16 birama yang di akhiri dengan sekuen sebanyak 4 birama.
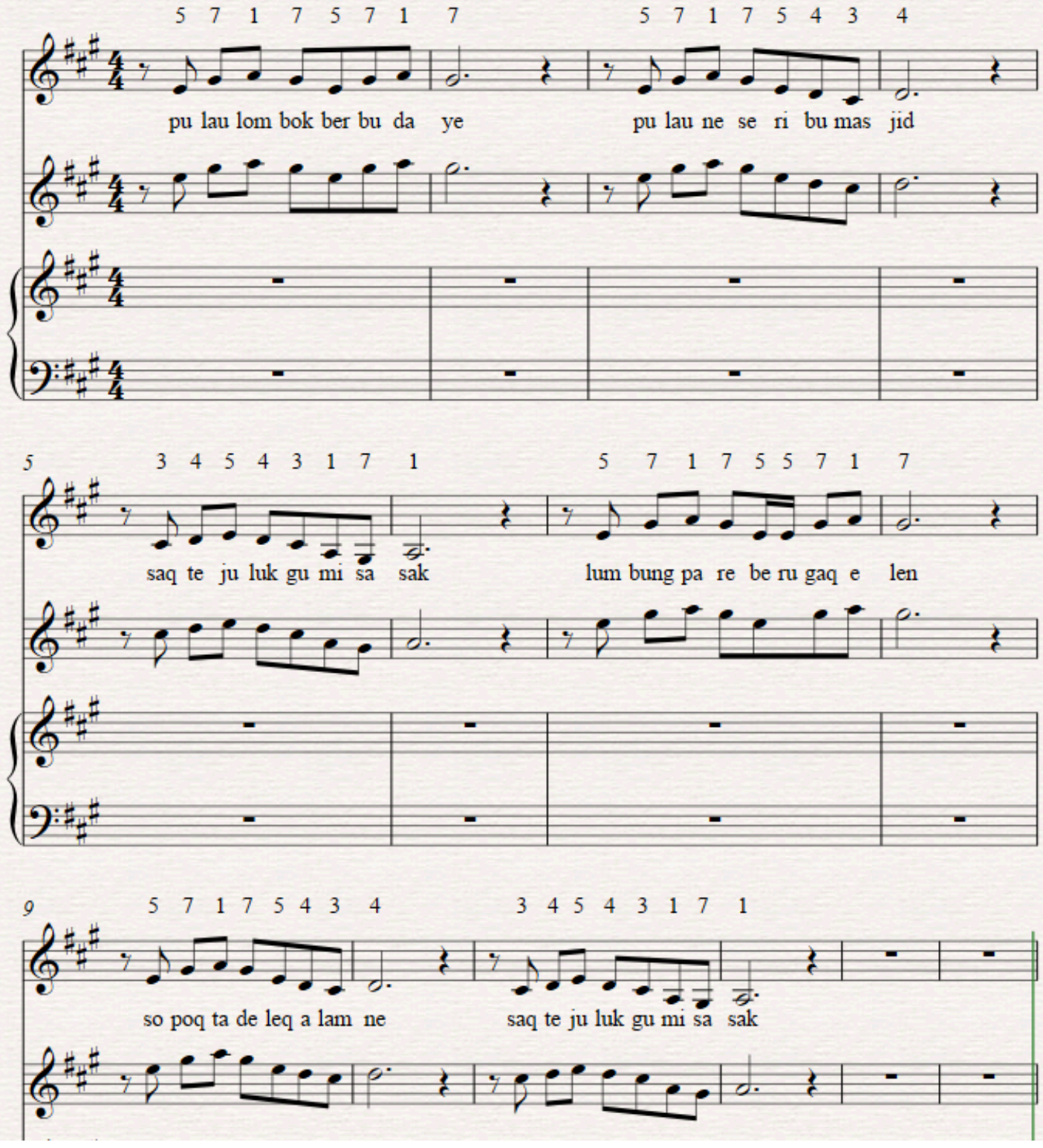

Gambar 3: Potongan Melodi Vocal Solo Pada Intro Lagu Bekayaq Dengan Menggunakan Tangga Nada Pelog (1-3-4-5-7).

\section{Komposisi 3: Matur Tampiasih}

Untuk komposisi ketiga, Matur Tampiasih, memberi makna rasa syukur. Makna rasa syukur ini mengacu pada rasa syukur atas nikmat ALLAH yang telah menciptakan alam semesta yang begitu untuk indah untuk manusia. Perancangan alat musik yang digunakan untuk komposisi ini terdiri dari gitar, gitar bass, gamelan saron dan keyboard.

Komposisi lagu ini berdurasi 3 menit 41 detik dengan tempo moderato dengan nuansa pelog (DO-MI-FA-SOL-SI) pada bagian melodi vocal. komposisi ini terdiri dari lagu 2 bagian yaitu bentuk A dan B. Lagu ini menggunakan akord dan tangga nada 3 kres (\#) Mayor. Lagu ini 
dimulai dari akor 5 Mayor sebagai akor pengiring pada tema awal lagu. Komposisi Lagu ini terbilang berbeda dari bentuk lainnya, karena lagu ini di mulai dari reff langsung atau bentuk B dijadikan sebagai intro.

Maksud dari cara ini adalah sebagai bentuk spontanitas anak muda untuk mengucapkan rasa terima kasih kepada pemilik semesta alam yang telah memberikan anugerah terindah berupa alam semesta dan seisinya. Lagu ini agak enerjik, terasa pada bagian motif ritme pada gitar, dan supaya terkesan rame dan mengajak semua orang untuk selalu bersyukur. Pada bagian A terdapat Frase anteseden dan Frase konsekuen. Pada bagian B juga terdapat frase anteseden dan konsekwen. Lagu ini sangat ringan dan mudah untuk dipahami tanpa harus menimbulkan kontroversi pada bagian lirik.

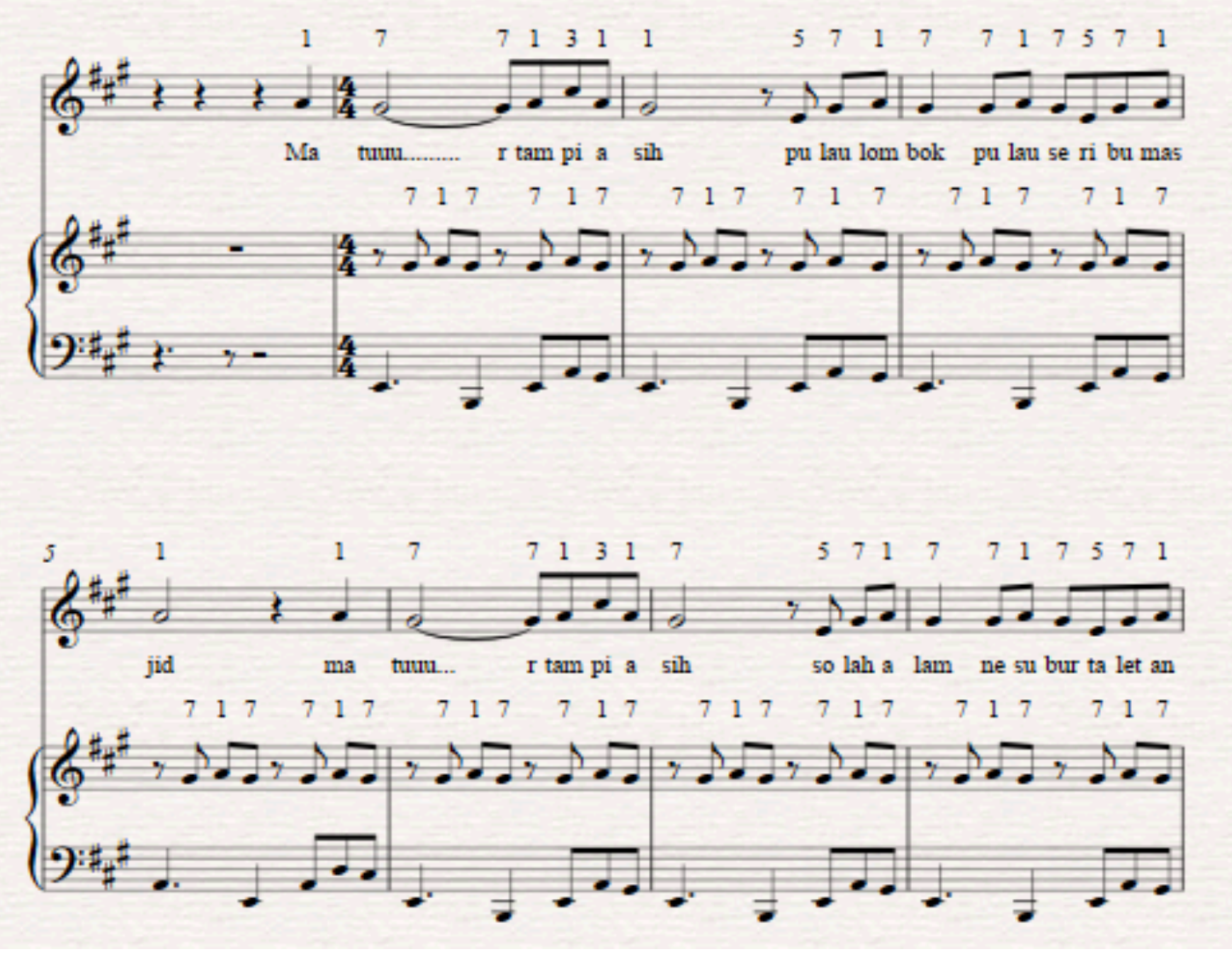

\section{Gambar 4: Potongan Melodi Vocal Matur Tampiasih Dan Melodi Iringan Dengan Menggunakan Tangga Nada Pelog (1-3-4-5-7).}

\section{Komposisi 4: Alam Dese}

Alam Dese berarti alam pedesaan, yang menggambarkan suasana tenang dengan menggunakan notasi bernuansa pelog (DO-MI-FA-SOL-SI) terasa sejuk, damai, jauh dari hiruk pikuk kota. Alam Dese yang berarti alam pedesaan, pada bagian komposisi ini penulis akan menceritakan tentang bagaimana menggambarkan suasana desa yang tenang dan damai, jauh dari keramaian dan kebisingan tatanan kehidupan kota. Alat musik yang akan digunakan dalam komposisi ini adalah gitar, string keyboard dan seruling bambu. 
Komposisi lagu saat ini berdurasi 4 menit 59 detik dengan 86 birama dalam tempo Andante dan menggunakan tangga nada 4 kres (\#) Mayor yang dimulai dengan akor 4 Mayor pada intro. Bentuk komposisi ini terdiri dari 2 bagian yaitu bentuk $A$ dan $B$. pada bagian intro terdiri dari 8 birama, bentuk $A$ terdiri dari 10 birama, bentuk $A^{\prime} 10$ birama, dan pada bentuk $B$ terdiri dari 14 birama. Pada bagian interlude terdapat 16 birama dengan melodi gitar akustik yang memberikan nuansa alami dan kedamaian suasana alam desa. Kembali ke pengulangan pada bagian A' kemudian ke bagian B hanya satu kali saja sebanyak 14 birama diakhiri dengan pengulangan motif melodi/sekuen 4 birama dan lagu berakhir.

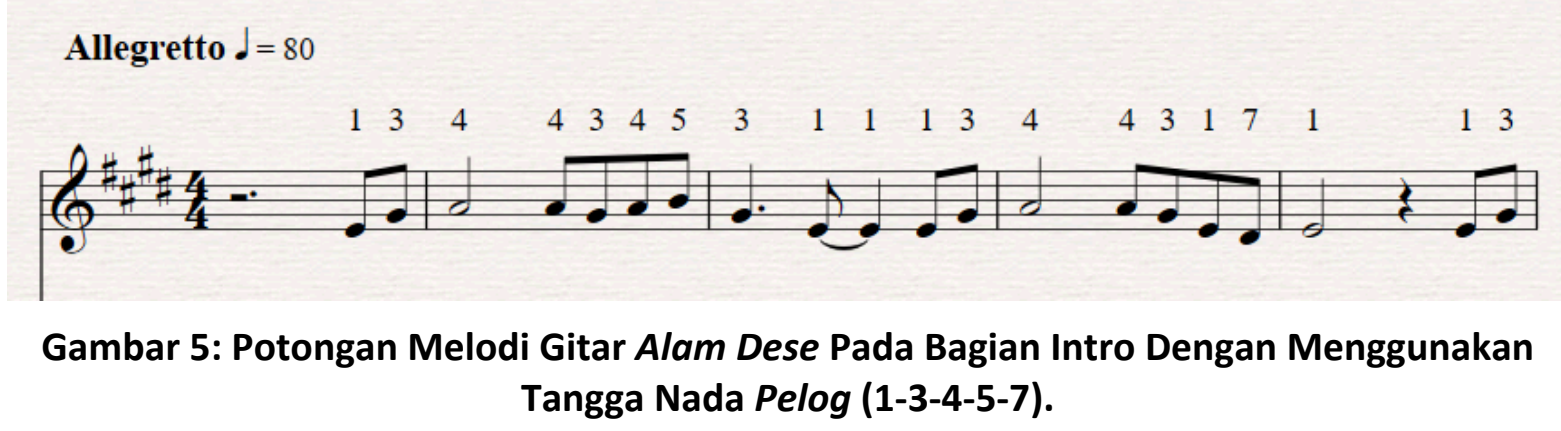

\section{Komposisi 5: Lalo Midang}

Selanjutnya, komposisi keempat adalah Lalo Midang yang berarti pergi ke rumah seorang wanita untuk membuktikan seberapa besar cinta dan keseriusan dia terhadap wanita yang dikunjunginya. Lalo Midang biasanya dilakukan di waktu malam dan menggambarkan situasi seorang pemuda bertemu dengan wanita yang dicintainya, bertujuan untuk membuktikan ketulusan cinta Kelampan Bajang. Alat musik yang digunakan dalam komposisi ini adalah, gitar, gitar bass, drum, keyboard, vokal dan kuartet gesek. Lagu ini akan di selipkan motif melodi bernuansa sasak, baik pada melodi vokal maupun motif melodi pada instrumennya.

Komposisi lagu ini berdurasi 3 menit 50 detik dengan tempo moderato dengan nuansa Selendro (DO-RE-MI-SOL-LA) pada bagian awal melodi vokal yang menceritakan tentang seorang anak muda yang menceritakan gadis jilbab putih dengan pakaian berwarna biru yang cantik alami yang sangat santun dan beretika yang membuat anak muda jatuh cinta dan ingin bertamu ke rumahnya untuk lalo midang. lagu ini terdiri dari lagu 3 bagian yaitu bentuk A, B dan C. Lagu ini menggunakan akor dari tangga nada 3 kres (\#) Mayor.

Komposisi lagu ini terbilang berbeda dari bentuk lainnya, karena melodi lagu ini bernuansa selendro. Dinamika pada lagu ini tidak ada yang menunjukkan perubahan yang signifikan, hanya pada bagian bentuk B terdapat pola ritme yang sedikit berbeda sebagai variasi menuju ke bentuk $C$. pengulangan secara harfiah bentuk $C$ terjadi pada bagian setelah interlude sebanyak 2 kali. 

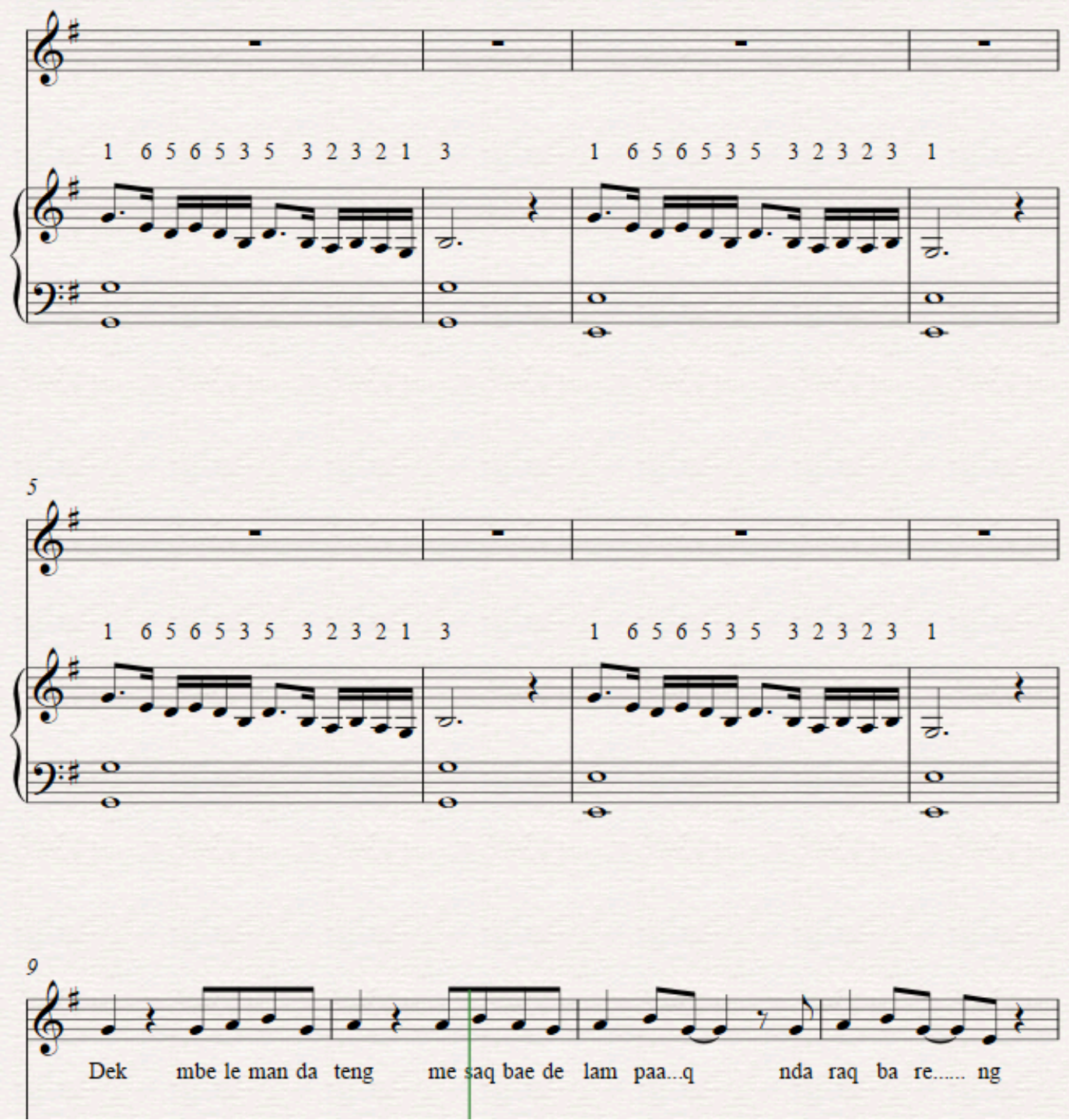

\section{Gambar 6: Potongan Motif Melodi Pada Bagian Intro Lagu Lalo Midang Dengan Menggunakan Tangga Nada Slendro (1-2-3-5-6).}

\section{Komposisi 6: Merariq}

Kemudian bagian terakhir adalah Merariq atau Melaiq'an yang artinya menikah dengan cara melarikan diri atau mencuri seorang wanita. Dalam tradisi Merariq atau Melaiq'an, yang memiliki arti mencuri pengantin wanita oleh pengantin pria, dari rumah pengantin wanita ke tempat keluarga atau kerabat pengantin pria, Melaiq'an merupakan proses sakral dalam tradisi suku sasak. Dalam komposisi ini, peneliti akan memberikan suasana Merariq dengan mengeksplorasi nada-nada instrumen gamelan khas sasak. Komposisi ini bertemakan tradisi merariq dalam tradisi sasak yang terjadi pada malam hari. Perencanaan awal komposisi ini menggunakan alat musik seruling, terompong (di antara alat musik yang terdapat dalam ansambel gamelan), gitar, gitar bass, keyboard, drum, vokal, serta 
kuartet gesek. Komposisi saat ini berdurasi 5 menit 11 detik dengan 127 birama dalam tempo moderato dengan menggunakan tangga nada 1 kruis (\#) Mayor. Bentuk komposisi ini terdiri dari 3 bagian yaitu bentuk $A, B$ dan $C$. pada bagian intro terdiri dari 12 birama, bentuk $A$ terdiri dari 8 birama, bentuk $A^{\prime}$ terdiri dari 9 birama, dan pada bentuk $C$ terdiri dari 10 birama, kemudian $C^{\prime}$ terdiri dari 13 birama. Pada bagian interlude terdapat 8 birama dengan penekanan pada instrument terompong gamelan yang mendominasi, yang dimainkan dalam tangga nada pelog (DO-MI-FA-SOL-SI) yang membentuk motif melodi sasak dengan tujuan sebagai unsur yang memperkuat identitas dan mewakili nuansa tradisi sasak. Kembali ke pengulangan pada bagian $B$ dan peneliti akan memberikan pengulangan secara harfiah pada bagian $C$ dengan 40 birama dengan maksud menegaskan suatu pesan untuk meningkatkan perhatian supaya makna dan pesan lirik dalam lagu tersebut dapat tersampaikan dengan baik.
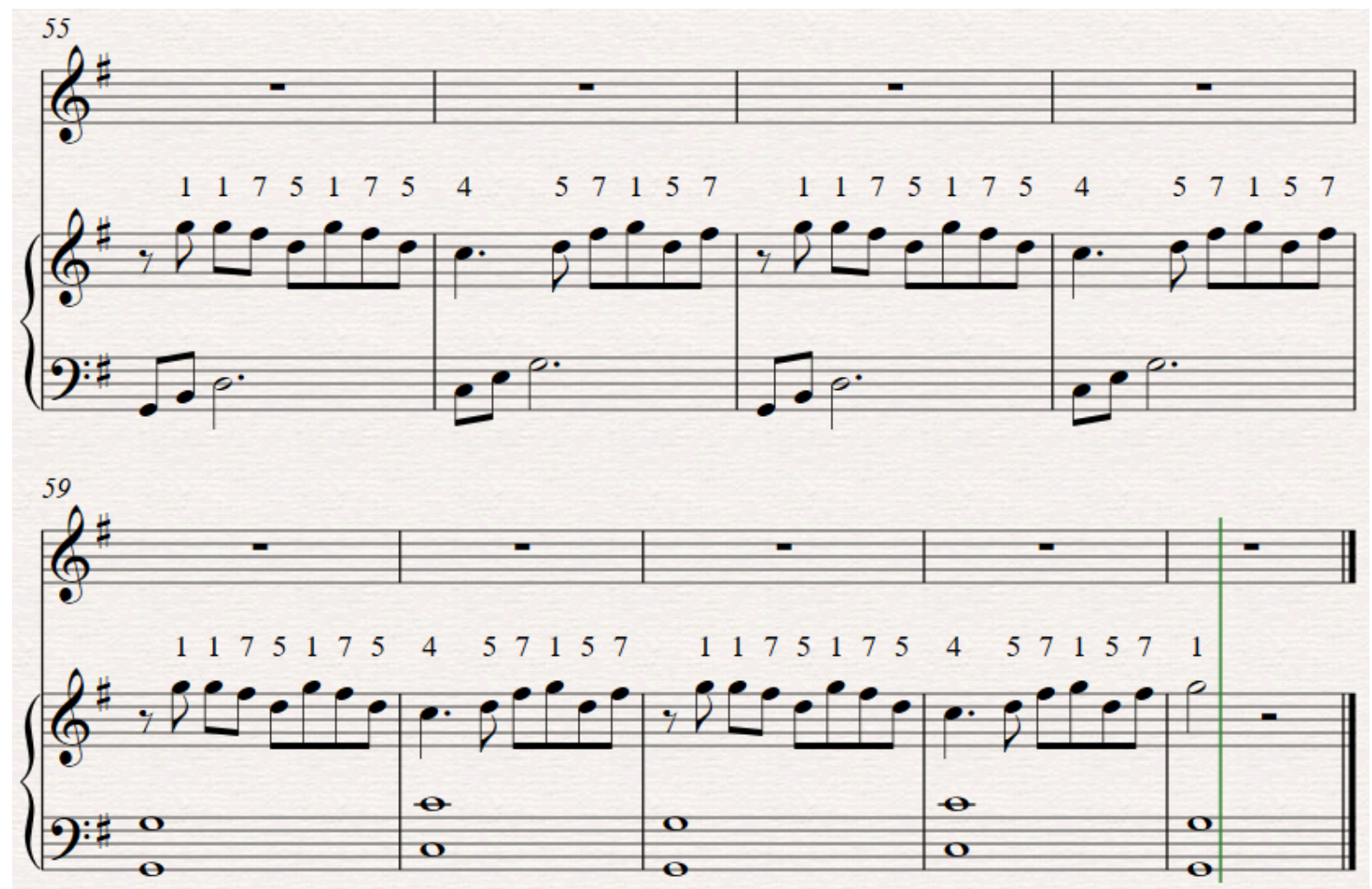

Gambar 7: Potongan Motif Melodi Lagu Merariq Pada Bagian Interlude Dengan Menggunakan Tangga Nada Pelog (1-3-4-5-7).

\section{Pembahasan}

Tema komposisi ini adalah Kelampan Bajang. Kelampan artinya perjalanan dan Bajang adalah anak muda, Kelampan Bajang dapat ditafsirkan sebagai kisah perjalanan yang menceritakan tentang kehidupan sehari-hari pemuda Sasak di Lombok. Kelampan bajang kemudiannya akan menjadi beberapa bagian berdasarkan waktu yaitu, waktu pagi akan ada 2 komposisi lagu dengan judul Lalo Bekuliq dan Bekayaq. Lalo bekuliq menceritakan tentang pemuda desa yang harus bekerja dan menyambut pagi dengan penuh semangat. Kemudian Bekayaq menceritakan tentang pemuda bersemangat sambil bernyanyi mengalunkan lagu dalam nuansa dan unsur tradisional.

Pada dasarnya lalo bekuliq dapat di maknai secara luas, yaitu menggambarkan seorang yang pekerja keras, banting tulang dan tidak mengeluh, menceritakan tentang seorang laki - 
laki yang harus keluar rumah di waktu pagi demi menghidupi anak istri. Menceritakan pemuda pekerja keras yang hidup di rantauan, menggambarkan pemuda desa yang bekerja di sawah dan lain sebagainya. Ada sebuah penggalan kalimat yang sering kita dengar pada masyarakat suku sasak yaitu "Bani Sugul, Bani Mate" yang peneliti pakai sebagai lirik lagu pada bagian reff. Bani sugul, Bani Mate jika di terjemahkan dalam bahasa Indonesia yang berarti Berani Keluar, Berani Mati, yang bermakna orang sasak itu jika sudah keluar rumah lalo bekuliq, tujuan utamanya adalah untuk anak istri di rumah, pantang menyerah untuk pulang sebelum membawa keberhasilan, jikapun ada hasil bekerja saat itu dia tidak akan menikmati hasil itu sebelum memberikan anak istrinya terlebih dahulu. Jika laki-laki itu adalah seorang pemuda lajang maka dia akan bekerja keras untuk menabung dalam mempersiapkan masa depan pernikahannya. Untuk memberikan nuansa tradisi pada bagian reff peneliti banyak menggunakan motif melodi dengan notasi $1 / 8$ dalam tangga nada slendro dengan akord 1 kres (\#) Mayor.

Bekayaq yang memiliki makna menyanyikan lagu dalam lirih bernuansa kedaerahan yang khas. Melodi vocal pada bekayaq biasanya berjalan secara pararel dengan instrument tradisional seperti, gambus, seruling, saron dan beberapa instrumen tradisi lainnya. Pada dasarnya bekayaq akan di bawakan oleh siapapun, dan kapanpun, namun dalam hal ini memaknai bekayaq yang sering di lakukan oleh seorang pemuda desa untuk mengibur diri disela-sela aktifitas bekerja. Pada komposisi lagu bekayaq ini tidak menggunakan instrumen ritmis, melainkan hanya menggunakan instrument melodis dan instrument harmonis. Jika lagu lalo bekuliq terkesan enerjik, namun pada lagu ini terkesan santai dengan tempo moderato. pada motif melodi ini peneliti lebih banyak menggunakan not $1 / 8$ dengan tempo pelan sehingga terdengar agak magis dengan nuansa tangga nada pelog yang di mulai dengan akord 3 kres (\#) Mayor.

Pada siang hari akan ada 2 komposisi lagu iaitu komposisi lagu Matur Tampiasih dan komposisi lagu Alam Dese. Matur Tampiasih menceritakan seorang pemuda yang sedang duduk merenung dibawah pohon di pematang sawah, mensyukuri nikmat Allah SWT yang kuasa yang telah memberikan rahmat dan hidayahnya untuk hari itu. Berikutnya, Alam Dese menceritakan tentang alam desa, persahabatan, rasa syukur hidup di desa dengan keramahan dan kehangatan situasi dan masyarakat desa dengan alam yang subur yang diberkahi oleh Allah SWT yang maha kuasa.

Matur tampiasih yang berarti terima kasih, ungkapan rasa syukur dengan bahasa daerah yang paling halus dan sopan yang dimaknai oleh orang sasak di Lombok. Hampir tidak ada lagu sasak yang berjudul matur tampiasih, sehingga peneliti menggunakan kata ini sebagai salah satu judul komposisi lagu sekaligus menempatkan kata matur tampiasih pada motif melodi yang di nyanyikan secara berulang-ulang pada bagian reff. Lagu ini berbeda dengan komposisi lagu pop sasak pada umumnya. Keunikan lagu ini adalah komposisi di mainkan langsung dari reff.

Alam dese, Pada lagu alam dese pada dasarnya menceritakan tentang kegelisahan seseorang melihat sahabatnya pergi merantau meninggalkan kampung halaman. Rasa sedih yang mendalam di rasakan oleh orang-orang terdekat melihat salah seorang di antara mereka pergi merantau. Komposisi lagu ini merefresentasikan tentang situasi persahabatan yang di balut dengan suasana pedesaan yang sepi, sunyi, jauh dari kata ramai, sehingga lagu ini terdengar begitu menyayat dengan hanya menggunakan instrument seruling, gitar dan string 
keyboard. Nuansa pedesaan dengan motif melodi tangga nada pelog sangat terasa pada komposisi ini. Lagu ini di mulai dengan akord 4 kres (\#) Mayor.

Pada waktu malam terdapat 2 komposisi lagu yaitu komposisi lagu Lalo Midang dan Komposisi Merariq. Lalo Midang menceritakan tentang pria sasak pergi berkunjung kerumah wanita untuk membuktikan makna perasaan cinta terhadap wanita yang di datangi. Lalo midang akan di lakukan berulang kali, biasanya akan di lakukan di waktu luang setelah aktifitas bekerja pada siang hari. Makna lalo midang pada kompisisi ini adalah menceritakan tentang pemuda sasak yang sedang jatuh cinta, sehingga melodi-melodi pada komposisi ini dapat merefresentasikan orang yang sedang jatuh cinta. Untuk menguatkan nuansa kedaerahannya, peneliti menggunakan tangga nada slendro pada melodi intro dengan kombinasi not 1/16 yang di mulai dengan akord 1 kres (\#) Mayor.

Kemudian Merariq adalah satu tradisi sakral yang akan dilakukan oleh pria sasak sebagai calon pengantin pria untuk mengambil calon pengantin wanita dengan cara mencuri wanita itu dari rumah orang tuanya menuju tempat besebo yang berarti tempat persembunyian, sebagai tempat tujuan sebelum kedua calon pengantin tersebut di izinkan pulang kerumah mempelai pria oleh pemilik rumah tempat besebo. Calon pengantin pria dan wanita dijemput oleh pihak keluarga calon pengantin pria. Tradisi ini memang terdengar cukup kontroversial sehingga peneliti berusaha membuat alur cerita yang mudah di pahami. Agar lagu ini terdengar memiliki nuansa kedaerahan, peneliti memperkuat lagu ini dengan mengeksplorasi tangga nada pelog pada bagian interlude sebagai simbol kemeriahan pesta pernikahan dalam tradisi sasak.

Secara umum komposisi lagu sasak di Lombok menggunakan lirik berbahasa sasak. Peneliti juga dapat menyimpulkan beberapa permasalahan pada musik pop sasak, fenomena yang ditemukan antara lain tidak ada lagu berbahasa Sasak yang lengkap dalam transkrip dan aransemen, banyak musisi mengaransemen lagu dalam bahasa Sasak tetapi sering menimbulkan kontroversi pada lirik dan musik, banyak musisi muda berbakat mengcover ulang lagu-lagu noname pada beberapa lagu yang dibawakan oleh banyak penyanyi pop di Lombok, banyak lagu pop sasak tetapi sebagian besar tidak merefresentasikan budaya daerah dari sisi lirik dan musik. Untuk membandingkan karya komposisi kelampan bajang dengan komposisi musik lainnya di Lombok yaitu, 1) peneliti dapat mentranskripsikan karya baik secara lirik dan aransemen musik, karena pada kenyataannya lagu-lagu berbahasa sasak tidak terdokumentasi dengan baik, dan secara historis tidak dapat divalidasi karena penciptanya tidak diketahui alias noname misalnya kadal nongak, tegining teganang, angin alus, apakah lirik dan notasi melodinya benar seperti itu?, belum ada yang mempertanggung jawabkan hingga saat ini. 2) dengan berbekal ilmu pengetahuan musik, peneliti dapat mengeksplorasi tangga nada pelog dan slendro pada karya komposisi kelampan bajang, dan hampir sebagian besar musisi di Lombok bermusik dan menciptakan karya menggunakan insting bukan mengacu pada ilmu pengetahuan dan teori musik, sehingga menyebabkan proses penciptaan karya terkesan instan dan tidak memiliki perhitungan. 3) Peneliti menggunakan lirik berbahasa sasak yang netral yang mudah untuk di pahami oleh semua kalangan masyarakat suku sasak di Lombok, tentunya tidak akan menimbulkan kontroversi karena peneliti sudah mempertimbangkan sesuai dengan budaya daerah di Lombok.

Lagu-lagu berbahasa Sasak yang beredar di masyarakat Lombok riskan atau rawan menimbulkan kontroversi, baik dari segi lirik dan komposisi musik. Tahun 2009, 2017, termuat di media cetak dan online bahwa ada 40 hingga ratusan lagu berbahasa Sasak dicekal oleh 
KPID NTB. Untuk iitu saya berharap komposisi lagu ini bisa merefresentasikan kehidupan budaya anak muda suku sasak di waktu pagi, siang dan malam. Selain penelitian seni kreatif seperti desain studi seni kreatif, practice-led maupun practice-based, penelitian ini lebih banyak menggunakan metode yang dikenal sebagai autoetnografi.

\section{Kesimpulan}

Kelampan Bajang bertujuan untuk mengedukasi pemuda melalui sebuah karya dengan mengemas komposisi musik pop daerah dengan sederhana dan mudah untuk di mainkan, di pahami dan dinyanyikan, tentunya dengan harapan bisa mempengaruhi kehidupan pada sisi yang positif pada masyarakat umum dan masyarakat di Lombok pada khususnya. Dengan terciptanya karya komposisi dengan tema kelampan bajang ini, peneliti berharap kepada masyarakat umum dan musisi-musisi muda di Lombok pada khususnya, untuk jangan pernah menyerah dalam berproses baik itu latihan mengasah kemampuan musikalitas atau pun dalam berkarya seni.

Terkadang kita tidak menyadari apa yang ada di sekitar kita bisa melahirkan dan menciptakan sebuah ide yang berdampak positif pada diri kita. Tulisan ini menunjukan bahwa musik tidak hanya sekedar bunyi, melodi, dan irama yang teratur, tetapi musik juga merupakan hasil dari aktivitas manusia dalam mengolah bunyi sebagai media ekspresi dalam segala suasana, waktu dan tempat. Semoga penelitian dan karya komposisi ini bisa menghadirkan warna dalam musik pop daerah, menjadi rujukan untuk penelitian selanjutnya dan menjadi media dalam khazanah perkembangan musik di Lombok.

\section{Referensi}

Abimanyu, D. E. Y., \& Harwanto, D. C. (2019). Aransemen lagu "lelo ledung" menggunakan idiom-idiom pentatonik gamelan jawa pada piano solo. Musikolastika: Jurnal Pertunjukan Dan Pendidikan Musik, 1(2), 87-100. doi:10.24036/MUSIKOLASTIKA.V1I2.29

Abu Bakar Nor Azura. (2014). Modul asas pengajaran dan pembelajaran nyanyian lagu melayu asli, 16. Retrieved from https://melayu.library.uitm.edu.my/1743/1/Modul Asas Pengajaran Dan Pembelajaran Nyanyian Lagu Melayu Asli.pdf

Anton. (2009). Sepuluh lagu sasak terancam ditarik. Retrieved 9 August 2021, from https://www.antaranews.com/berita/138579/sepuluh-lagu-sasak-terancam-ditarik

Asriyani, N., \& Rachman, A. (2019). Enkulturasi musik keroncong oleh o.k gema kencana melalui konser tahunan di banyumas. Musikolastika: Jurnal Pertunjukan Dan Pendidikan Musik, 1(2), 74-86. doi:10.24036/MUSIKOLASTIKA.V1I2.27

Awaludin. (2014). Kpid ntb cekal lagu 'jual cobek'. Retrieved from https://www.antaranews.com/berita/453529/kpid-ntb-cekal-lagu-jual-cobek

Ayderova, V., Wong, W. H. Y. @ C., Augustine, C., \& Arshad, S. F. (2020). Learning ornament signs through transcriptions of malaysian folk songs in an applied music course. International Journal of Academic Research in Business and Social Sciences, 10(5). doi:10.6007/IJARBSS/V10-I5/720 
Creswell, J. W. (2016). 30 essential skills for the qualitative researcher, 292.

Gauntlett, D. (2021). What is practice-based research? Retrieved from https://davidgauntlett.com/research-practice/what-is-practice-based-research/

Isyak, F. N. (2018). Oral transmission and stylistic issues in malay asli song in johor. [Master's Thesis, Universiti Malaya]. University of Malaya Students Repository. Retrieved from http://studentsrepo.um.edu.my/8949/2/NIDZAM_FINAL_20APRIL2018.pdf

Kompas.com. (2009). Sepuluh lagu sasak terancam ditarik. Retrieved 9 August 2021, from https://www.youtube.com/watch?v=dWnBbw96jow

KOMPAS.COM. (2009). Fpnbs lombok dukung pencekalan lagu sasak. Retrieved 21 August 2021, from https://nasional.kompas.com/read/2009/04/24/02052367/ Oase Cakrawala

Kristanto, A. (2020). Urgensi kearifan lokal melalui musik gamelan dalam konteks pendidikan seni di era 4.0. Musikolastika: Jurnal Pertunjukan Dan Pendidikan Musik, 2(1), 51-58. doi:10.24036/MUSIKOLASTIKA.V2I1.39

Mazlan, C. A. N. (2021). Pembangunan dan penilaian buku panduan pembelaajaran teknik pengharmonian gitar jaz menggunakan lagu melayu asli. Universiti Pendidikan Sultan Idris, Perak, Malaysia. Retrieved from https://ir.upsi.edu.my/detailsg.php?det=5620\&highlight=chamil arkhasa nikko

Mazlan, C. A. N, \& Abdullah, M. H. (2020). Utilizing pragmatism principles in learning jazz guitar reharmonization technique using malay asli song. International Journal of Applied and Creative Arts, 3(1), 54-66. doi:10.33736/IJACA.2188.2020

Mazlan, C. A. N, Abdullah, M. H., Arshad, S. F., Latif, M. K. A., Imam, R. M., \& Daud, I. S. (2020). Satu Tinjauan muzikologi lagu melayu asli. Jurai Sembah, 1(2), 14-26. doi:10.37134/JURAISEMBAH.VOL1.2.2.2020

Mazlan, C. A. N, Ramli, N. A. M., Abdullah, M. H., \& Uyub, A. I. (2021a). E-learning gamelan ensemble playing techniques. Jurnal Seni Musik, 10(1), 1-4. doi:10.15294/JSM.V10I1.44076

Mazlan, C. A. N, Ramli, N. A. M., Abdullah, M. H., \& Uyub, A. I. (2021b). E-learning gamelan ensemble playing techniques. Jurnal Seni Musik, 10(1), 1-4. doi:10.15294/jsm.v10i1.44076

Rosly, S. R. M. (2018). Kajian ornamentasi dalam muzik melayu asli. Permainan Violin Gaya Hamzah Dolmat. [Master's Thesis, Universiti Malaya]. University of Malaya Students Repository. Retrieved from http://studentsrepo.um.edu.my/8607/

Sasongko, M. H., \& Supriyadi, S. (2021). Dialektika musik tradisi atas musik modern pada musik hybrid di keraton yogyakarta. Musikolastika: Jurnal Pertunjukan Dan Pendidikan Musik, 3(1), 9-17. doi:10.24036/MUSIKOLASTIKA.V3I1.59

Shah, S. M., \& Adam Masumi, M. (2016). Teaching traditional music in malaysian schools: Considering the Cultural Context. International Journal of Learning and Teaching, 8(1), 69. doi:10.18844/IJLT.V8I1.511 
Shah, S. M., \& Masumi, M. A. (2016). Teaching traditional music in malaysian schools: Considering the Cultural Context. International Journal of Learning and Teaching, 8(1), 69-76. doi:10.18844/IJLT.V8I1.511

Suarantb.com. (2017). Kpid ntb cekal 40 lagu sasak. Retrieved 9 September 2021, from https://www.suarantb.com/kpid-ntb-cekal-40-lagu-sasak/

Wimbrayardi, W. (2019). Musik tradisi sebagai salah satu sumber pengembangan karya cipta. Musikolastika: Jurnal Pertunjukan Dan Pendidikan Musik, 1(1), 7-12. doi:10.24036/MUSIKOLASTIKA.V1I1.10

Zitierung, E., Ellis, C. ;, Adams, T. E., \& Bochner, A. P. (2011). Autoethnography: an overview. Historical Social Research, 36(4), 273-290. doi:10.12759/hsr.36.2011.4.273-290 